\title{
La inaudita STC 108/2017, de 21 de septiembre, sobre la Ley del Parlamento de Cataluña 8/2015, de 10 de junio, de creación del municipio de Medinyà
}

\section{The unprecedented Constitutional Court's Judgment no. 108/2017, of September 21, about Law of the Parliament of Catalonia 8/2015, of June 10, of creation of the municipality of Medinyà}

\author{
Miquel Pons Portella \\ Abogado \\ ponsportella@gmail.com
}

\section{NOTA BIOGRÁFICA}

Abogado en Garrigues (Barcelona) (Área de Derecho Administrativo). Graduado en Derecho (itinerario de Derecho Público) (Universitat Pompeu Fabra de Barcelona, 2013). Máster en Abogacía (Universitat Oberta de Catalunya, 2016). Premio a la Excelencia (Cátedra Mutualidad de la Abogacía Española, 2016). Ilustre Colegio de Abogados de Barcelona. Máster en Derecho Canónico para Profesionales del Foro (Universidad Pontificia de Salamanca, 2017).

\section{RESUMEN}

El Tribunal Constitucional, con su Sentencia núm. 108/2017, de 21 de septiembre, ha declarado inconstitucional la Ley del Parlamento de Cataluña 8/2015, de 10 de junio, de creación del municipio de Medinyà. Se trata de una localidad de la provincia de Girona que ha luchado desde la década de 1970 por su segregación municipal, llegando incluso a tramitarse un expediente singularmente convulso que acabó siendo denegado en 2003 por carecer la población de suficientes habitantes. Su creación mediante ley fue concebida entonces como la única posibilidad para satisfacer las aspiraciones de Medinyà. Sin embargo, interpuesto recurso por el Presidente del Gobierno, el Tribunal Constitucional llega a la conclusión de que la Ley de creación del municipio de Medinyà incurre en un vicio insalvable de inconstitucionalidad mediata al no respetar el mínimum demográfico que para la constitución de nuevos municipios contempla la normativa básica del Estado sobre régimen local desde su reforma de 2013. El razonamiento del Tribunal es muy claro, pero su pronunciamiento no despeja en absoluto las dudas que genera el modo cómo tendrá que cumplirse.

\section{PALABRAS CLAVE}

Alteración de términos; municipios; régimen local; segregación; Tribunal Constitucional.

\begin{abstract}
The Constitutional Court, with its Judgment no. 108/2017, of September 21, has declared unconstitutional the Law of the Parliament of Catalonia 8/2015, of June 10, of creation of the municipality of Medinyà. It is a town in the province of Girona that has struggled since the 1970s for its municipal segregation, even processing a singularly convulsive proceeding that ended up being denied in 2003 for lacking the town of enough inhabitants. Its creation by law was conceived then as the only possibility to satisfy the aspirations of Medinyà. However, filed an appeal by the President of the Government, the Constitutional Court reaches the conclusion that the Law of creation of the municipality of Medinyà incurs an unbridgeable defect of
\end{abstract}


REALA. Nueva Época - N. 9 9, Abril 2018 - ISSN: 1989-8975 - DOI: 10.24965/reala.v0i9.10472 - [Págs. 148-164]

La inaudita STC 108/2017, de 21 de septiembre, sobre la Ley del Parlamento de Cataluña 8/2015, de 10 de junio, de creación..

Miquel Pons Portella

mediate unconstitutionality by not respecting the demographic minimum that for the constitution of new municipalities contemplates the State basic regulations on the local regime since its 2013 reform. The reasoning of the Tribunal is very clear, but its pronouncement does not at all clear up the doubts that the way it will have to be fulfilled generates.

\section{KEYWORDS}

Terms alteration; municipalities; local regime; segregation; Constitutional Court.

\section{SUMARIO}

INTRODUCCIÓN. 1. LA TORTUOSA HISTORIA DEL MUNICIPIO DE MEDINYÀ. 1.1. LA «INCORPORACIÓN VOLUNTARIA»A SANT JULIÀ DE RAMIS (1972). 1.2. EL PROCESO FRUSTRADO DE SEGREGACIÓN MUNICIPAL (1995-2003). 1.3. GÉNESIS Y CONTENIDO DE LA LEY DEL PARLAMENTO DE CATALUÑA 8/2015, DE 10 DE JUNIO. 2. EL LITIGIO CONSTITUCIONAL SOBRE LA LEY DE CREACIÓN DEL MUNICIPIO DE MEDINYÀ (STC 108/2017, DE 21 DE SEPTIEMBRE). 2.1. LOS ARGUMENTOS DEL GOBIERNO. 2.2. LOS ARGUMENTOS DE LA COMUNIDAD AUTÓNOMA DE CATALUÑA. 2.3. LA DECISIÓN DEL TRIBUNAL CONSTITUCIONAL. 3. CONCLUSIONES. 5. REFERENCIAS BIBLIOGRÁFICAS.

\section{INTRODUCCIÓN}

Con la STC 108/2017, de 21 de septiembre, el Tribunal Constitucional ha tomado una decisión ciertamente inaudita. Es inaudito -en el sentido de sorprendente por insólito-no tanto el pronunciamiento que contiene, una declaración de inconstitucionalidad, como la consecuencia que en un futuro inmediato va a tener: la supresión del municipio de Medinyà, en la provincia de Girona, a resultas de haberse declarado inconstitucional -y, por lo tanto, nula- la Ley del Parlamento de Cataluña 8/2015, de 10 de junio, de creación del susodicho municipio.

Comprender cabalmente lo extraordinario del caso, nuestro propósito con este comentario de la STC 108/2017, requiere estudiar antes por qué motivos Medinyà fue segregado en municipio independiente mediante una ley, algo poco frecuente en nuestro Derecho Local (San Martín Segura, 2010: 261-268). A este asunto dedicaremos todo el capítulo 1 del presente trabajo, para luego acometer -en el capítulo 2- el análisis ordenado y detallado de la STC 108/2017. Al final, en el habitual capítulo de conclusiones, apuntaremos con brevedad el procedimiento seguido recientemente para cumplimiento a esta particular decisión del Tribunal Constitucional.

\section{LA TORTUOSA HISTORIA DEL MUNICIPIO DE MEDINYÀ}

El pueblo de Medinyà, situado al noreste de la ciudad de Girona, aparece mencionado por primera vez en documentos oficiales del siglo XI. Se tiene constancia de que en 1380 existían allí 34 hogares ubicados alrededor del castillo de Medinyà, cuya capilla se convertiría -hacia la década de 1760- en la parroquia del lugar. A finales del mismo siglo XVIII, la localidad tenía 369 habitantes, que llegaron a 463 en el censo de 1860. Disminuiría su población a partir de 1900, aunque hacia 1970 había vuelto a incrementarse hasta los 446 vecinos 1 .

\subsection{LA «INCORPORACIÓN VOLUNTARIA»A SANT JULIÀ DE RAMIS (1972)}

Fue entonces, mediante el Decreto 2049/1972, de 13 de julio, cuando se aprobó «la incorporación voluntaria del Municipio de Mediñá al limítrofe de San Julián de Ramis, de la provincia de Gerona» (art. 1). Es importante tener en cuenta los antecedentes de esta decisión, que constan en su breve preámbulo:

«Los Ayuntamientos de Mediñá y de San Julián de Ramis, de la provincia de Gerona, acordaron, con el quórum legal, solicitar y aceptar, respectivamente, la incorporación del primero de los Municipios al segundo, por considerarla beneficiosa para los intereses generales de uno y otro.

\footnotetext{
1 Información extraída de la Gran Enciclopèdia Catalana, disponible en Internet a través de la dirección <https://www.enciclopedia.cat> (consulta realizada el 22 de octubre de 2017).
} 
Cumplidas en el expediente las reglas de procedimiento que establecen los Cuerpos legales vigentes en la materia, obran en el mismo los informes favorables de los Organismos Provinciales consultados, y se acredita la existencia de los notorios motivos de conveniencia económica y administrativa exigidos en el art. 14, en relación con el 13, apartado c) de la Ley de Régimen Local para que proceda acordar la incorporación».

En aquel momento, se hallaba en vigor el texto articulado de la Ley de Régimen Local aprobado por Decreto de 16 de diciembre de 1950 (Orduña, 2005: 198), cuyos arts. 14 y 13 c) -como acabamos de ver- facultaban al Gobierno, «cuando existan notorios motivos de necesidad o conveniencia económica o administrativa», para «incorporar uno o más Municipios a otro». Además, poco tiempo antes había sido aprobada la Ley 48/1966, de 23 de julio, sobre modificación parcial del Régimen Local, que creó el Fondo Nacional de Haciendas Municipales como medida de «estímulo económico para fomentar las Agrupaciones a efectos del sostenimiento común del servicio a una ulterior racionalización de nuestra organización territorial. El esfuerzo que la reforma exige no puede malgastarse en el desmenuzamiento de las participaciones entre unidades administrativas que, en la situación actual, no resultan viables como base de prestación de los servicios locales». En efecto, el art. 17.1 de la Ley 48/1966 estableció que los beneficios de dicho Fondo serían aplicables «en los casos de fusión o incorporación de Municipios que reúnan un total de población no superior a los cinco mil habitantes». Tales incentivos dieron lugar a una disminución relevante del número de municipios en España -de 9.202 a 8.022 entre 1960 y 1981 (Quintana López, 2014: 31)- que también afectó, como acabamos de ver, al pueblo de Medinyà.

Por todo ello, parece que deberían ser matizadas las alegaciones formuladas por el Letrado del Parlamento de Cataluña ante el Tribunal Constitucional en el sentido de que se trató de «una decisión "adoptada por un consistorio carente de los mínimos requisitos y garantías democráticos y de autonomía frente a los demás poderes públicos", lo que convertiría esa fusión en una integración municipal de "carácter forzado y antidemocrático" y en un "atentado contra la autonomía local y contra el derecho de los vecinos a contar con una entidad representativa propia"» [STC 108/2017, antecedente 6. ${ }^{\circ}$ a)]. El Decreto 2049/1972 tiene que ser ubicado en su justo contexto histórico: si bien es verdad -como leemos en el preámbulo, apartado II, de la Ley 8/2015- que los ayuntamientos responsables de dicha decisión no habían sido elegidos democráticamente, «ya que el país sufría la dictadura franquista, y que el mencionado decreto está firmado por el dictador Francisco Franco», no lo es menos que la incorporación fue «voluntaria» -cuando la propia Ley de Régimen Local entonces vigente contemplaba, entre otras medidas semejantes, la «agrupación forzosa» de municipios (arts. 38 y 39)- y que sirvió probablemente para que Sant Julià de Ramis pudiese beneficiarse de importantes subvenciones. Al fin y al cabo, en la actualidad incluso el Decreto Legislativo 2/2003, de 28 de abril, por el que se aprueba el Texto refundido de la Ley Municipal y de Régimen Local de Cataluña (en adelante, TRLMRLC), en su art. 20, contempla «medidas de fomento», sobre todo de índole económica, para la fusión y agregación de municipios.

\subsection{El proceso frustrado de segregación municipal (1995-2003)}

Sea como fuere, «la población -se explica también en el apartado II del preámbulo- mantuvo, desde un primer momento, la voluntad de que Medinyà recuperase su carácter de municipio, y el año 1995 se constituyó el Col·lectiu pro Medinyà Independent».

Esta asociación formaría, a finales de 1996, la comisión promotora prevenida en el apartado d) del art. 16 del Reglamento de Demarcación Territorial y Población de los Entes Locales de Cataluña (Decreto 140/1988, de 24 de mayo) $)^{2}$ y procedería seguidamente a presentar la correspondiente petición de iniciación del expediente de alteración del término municipal de Sant Julià de Ramis. De conformidad con el art. 19.2 del mismo Reglamento, dicha petición había de «concretarse con las firmas de los vecinos formalizadas ante el secretario del ayuntamiento o protocolizadas notarialmente». En este caso, los promotores de la independencia de Medinyà optaron por protocolizar ante notario las 334 firmas recabadas para solicitar la iniciación del referido expediente. Según lo dispuesto por los arts. 19.1 y 22.3, en sesión plenaria de fecha 12 de febrero de 1997, el Ayuntamiento de Sant Julià de Ramis acordó iniciar la instrucción del procedimiento. Tras haberse emitido todos los informes que se consideraron necesarios, el día 15 de mayo, se abrió el

2 Hoy derogado por el vigente Decreto 244/2007, de 6 de noviembre, por el que se regula la constitución y la demarcación territorial de los municipios, de las entidades municipales descentralizadas y de las mancomunidades de Cataluña. 
REALA. Nueva Época - N. 9 9, Abril 2018 - ISSN: 1989-8975 - DOI: 10.24965/reala.v0i9.10472 - [Págs. 148-164]

La inaudita STC 108/2017, de 21 de septiembre, sobre la Ley del Parlamento de Cataluña 8/2015, de 10 de junio, de creación..

Miquel Pons Portella

periodo de información pública exigido por el art. 23.1 mediante la inserción del correspondiente anuncio en el Diari Oficial de la Generalitat de Catalunya. A continuación, de acuerdo con el art. 25.1, se dio traslado de todo lo actuado al Departamento de Gobernación. Fue entonces, en fecha 12 de noviembre, cuando el director general de Administración Local requirió la subsanación de la petición presentada por la comisión promotora al entender que había incumplido el art. 19.2, antes transcrito, «ya que para considerar válidas las firmas de los vecinos que desean iniciar un expediente de alteración de términos municipales estas firmas deben hacerse ante una persona que pueda dar fe pública que la persona que comparece es la misma que la que firma». Así, según un criterio que sería confirmado en alzada por el consejero de Gobernación de la Generalitat el 3 de marzo de 1998, este precepto del Reglamento de Demarcación Territorial y Población de los Entes Locales «utiliza la disyuntiva "o" para equiparar la fe pública de dos fedatarios (secretario de ayuntamiento y notario) con el objetivo de permitir a los vecinos que escojan a uno de los dos, pero no para equiparar la fe pública del secretario municipal -que alcanza a la veracidad de las firmas que se realizan en su presencia- con la fe pública de un acta de protocolización -que alcanza tan sólo a la identidad de la persona que requiere al Notario para que extienda el acta-» ${ }^{3}$.

La decisión tomada por la Consejería de Gobernación sería recurrida por la comisión promotora ante la Sala de lo Contencioso-administrativo del Tribunal Superior de Justicia, pero, entretanto, el Parlamento autonómico aprobó una modificación de la Ley 8/1987, de 15 de abril, Municipal y de Régimen Local de Cataluña que iba a alterar el curso de los acontecimientos subsiguientes.

Al iniciarse el expediente de Medinyà, el art. 15 de esta Ley -todavía en su versión originaria- no exigía ningún mínimum poblacional para la creación de nuevos municipios por segregación ${ }^{4}$. Ello cambiaría con la Ley 13/1998, de 19 de noviembre, que modificó la Ley 8/1987 «en relación con los requisitos exigidos para constituir municipios nuevos». En su preámbulo, se explica que al aprobarse aquélla ya había conciencia de «la problemática derivada del hecho de que [...] en Cataluña había un número excesivo de municipios, situación que suponía una fragmentación que se consideraba una de las causas de la crisis municipal». Por ello, el mentado art. 15 «estableció la posibilidad de constituir nuevos municipios, pero con un carácter muy restringido». Además, a partir de entonces, la Consejería de Gobernación optó por hacer «una interpretación muy estricta de los requisitos legales que deben cumplirse para dar lugar a la constitución de nuevos municipios», aunque ello no evitó «la constitución de nuevos municipios como consecuencia de los pronunciamientos contenidos en sentencias judiciales». Ciertamente, desde la entrada en vigor de la Ley 8/1987, la Generalitat de Cataluña se había visto obligada a constituir hasta tres municipios en cumplimiento de una Sentencia judicial: Salou (Decreto 326/1989, de 19 de diciembre) ${ }^{5}$, Riu de Cerdanya (Decreto 216/1997, de 30 de julio) ${ }^{6}$ y Sant

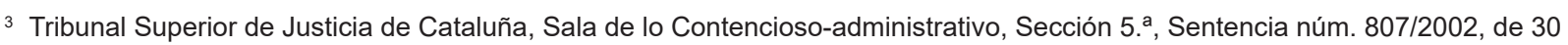
de octubre (recurso contencioso-administrativo núm. 715/1998), FJ $1 .^{\circ}$ y $3 .^{\circ}$

4 Su contenido literal era el siguiente:

«1.Podrán crearse nuevos municipios por segregación sólo cuando concurran todos los requisitos siguientes:

a) Existir núcleos de población territorialmente diferenciados.

b) Contar, los municipios resultantes, con el territorio y los recursos suficientes para el cumplimiento de las competencias municipales.

c) No comportar, la segregación, disminución de la calidad media de los servicios que se prestaban en el municipio.

2. Sin perjuicio del requisito establecido por el apartado 1.b), es preciso asimismo justificar que la segregación comporta una mejora objetiva en la prestación de los servicios del nuevo municipio».

${ }^{5}$ La segregación del núcleo de Salou del término municipal de Vila-seca i Salou para constituirse en municipio independiente, instada por una asociación de vecinos en abril de 1981, fue denegada por el Decreto 296/1986, de 25 de septiembre. Los interesados recurrieron ante la Sala competente de la Audiencia Territorial de Barcelona, que mediante su Sentencia de 1 de octubre de 1987 desestimó la impugnación. Sin embargo, la Sala Tercera del Tribunal Supremo -en Sentencia de 30 de octubre de 1989 (recurso de apelación núm. 267/1988)- declaró su nulidad, por carecer el Tribunal a quo de competencia objetiva para conocer de esta tipología de recursos, y entró en el fondo del asunto. Así, el Alto Tribunal anuló el Decreto 296/1986 y aprobó «la constitución [...] de un Municipio nuevo con la denominación y capitalidad en Salou». Por ello, el referido Decreto 326/1989 fue dictado para «llevar, íntegramente y debidamente, a efecto la Sentencia» que acabamos de comentar «y, en consecuencia, segregar el núcleo de Salou del municipio de Vila-seca y Salou [...]» (artículo único).

${ }^{6}$ El Decreto 10/1990, de 9 de enero, denegó la segregación municipal de la entidad local menor de Riu de Pendís del municipio de Bellver de Cerdanya al constatarse «que las circunstancias demográficas (51 habitantes en el padrón municipal vigente) y administrativas (según memoria que figura en el expediente, los vecinos de Riu de Pendís que lo promueven no consideran necesaria la creación de servicios administrativos propios) [...] evidencian una absoluta insuficiencia de medios personales para una adecuada prestación de los servicios mínimos obligatorios y de las funciones públicas necesarias en todos los entes locales». La Sala competente del Tribunal Superior de Justicia de Cataluña, por Sentencia de 17 de junio de 1993 (recurso contencioso-administrativo núm. 145/1991), anuló el referido Decreto 10/1990 y aprobó «la segregación de la entidad local menor de Riu de Pendís para constituirse en municipio independiente». Seguidamente, la representación procesal de la Generalitat de Cataluña interpuso ante la Sala Tercera del Tribunal Supremo el recurso de casación núm. 6030/1993, pero fue inadmitido por su Sección 6. ${ }^{a}$ mediante Auto de 27 de febrero de 1997. Así, tras declarar la Sala a quo la firmeza de la Sentencia de 17 de junio de 1993 y ordenar «que se cumpla su parte dispositiva», se dictó el 
REALA. Nueva Época - N. 9 9, Abril 2018 - ISSN: 1989-8975 - DOI: 10.24965/reala.v0i9.10472 - [Págs. 148-164]

La inaudita STC 108/2017, de 21 de septiembre, sobre la Ley del Parlamento de Cataluña 8/2015, de 10 de junio, de creación..

Miquel Pons Portella

Julià de Cerdanyola (Decreto 172/1993, de 28 de junio) ${ }^{7}$. Así las cosas, la Ley 13/1998 se aprueba tras constatarse que «de la normativa vigente y de la interpretación que se ha realizado de la misma se deduce que la [...] determinación de un número concreto de habitantes como un mínimo para poder constituir un nuevo municipio es un requisito necesario» para lograr que tales decisiones se tomen según "criterios objetivos de racionalidad, suficiencia y funcionalidad». Por ello, se introduce en el art. 15.1 de la Ley 8/1987 un nuevo apartado d) según el cual, para poder crear «nuevos municipios por segregación», pasa a ser necesario que «los municipios resultantes [...] [tengan] una población suficiente para asegurar su viabilidad. En todo caso, el nuevo municipio debe contar, como mínimo, con una población de 2.000 habitantes y el municipio o municipios de los que se segrega no deben bajar de este límite poblacional» ${ }^{8}$. La disposición final de la Ley 13/1998, en su apartado 2, determinó que este requisito demográfico, junto con los otros «establecidos en la presente Ley», serían «de aplicación a los expedientes de constitución de municipios nuevos por segregación que se hallen en tramitación en el momento de entrar en vigor la presente Ley» ${ }^{9}$.

La Sala de lo Contencioso-administrativo del Tribunal Superior de Justicia de Cataluña resolvió el recurso interpuesto contra el requerimiento del director general de Administración Local de fecha 12 de noviembre de 1997 con su Sentencia núm. 807/2002, de 30 de octubre. En la misma, la Sección 5. a de dicha Sala se muestra rotunda al afirmar que «la dicción del precepto -en alusión al art. 19.2 del Reglamento de Demarcación Territorial y Población de los Entes Locales- es suficientemente clara [...]. La norma exige que cuando la voluntad se exterioriza ante el secretario del ayuntamiento las firmas se formalicen delante de él, mientras que cuando el fedatario es el notario tan sólo se requiere que sean protocolizadas». Que el contenido propio de una acta de protocolización, según lo dispuesto por la normativa notarial, «le parezca insuficiente a la Administración, no puede implicar que se interprete el precepto intentando que diga lo que no dice, cuando su dicción es clara: "firmas protocolizadas notarialmente". Si la norma reglamentaria, que -no debe olvidarseemana del Gobierno de la Generalitat, hubiera querido que las firmas se legitimaran ante el notario, hubiera utilizado esa expresión en cuyo caso habría que acudir a la legitimación de firmas [...] para comprobar si se había cumplido este requisito. Pero como no es así, y como la norma es suficientemente clara y expresiva, no hay que acudir a otra interpretación que no sea la literal» ${ }^{10}$. Aplicando estas reflexiones al asunto de autos, el Tribunal Superior recuerda que, «en el caso examinado, no sólo se protocolizaron las firmas ante el notario, manifestando los comparecientes, bajo su responsabilidad y pena de falsedad en documento público, la legitimidad y autenticidad de las firmas, sino que fue el propio fedatario público el que [...] extendió un acta en la que da fe que comprobó una por una las firmas reconocidas como válidas [...]. No cabe duda que la comprobación realizada por el notario cuando se protocolizaron las firmas cumple la exigencia del

aludido Decreto 216/1997, de 30 de julio, para «llevar a efecto, íntegra y debidamente, la Sentencia», con la consiguiente constitución por segregación del municipio de Riu de Cerdanya.

7 El artículo único del Decreto 201/1990, de 30 de julio, denegó «la segregación del pueblo de Sant Julià de Cerdanyola del municipio de Guardiola de Berguedà (Berguedà) para constituirse en municipio independiente». Para adoptar esta decisión, la Generalitat tomó «en consideración [...] las circunstancias demográficas (235 habitantes en 1986), económicas (presupuesto evaluado del orden de 4 millones de pesetas, procedente en un $43,5 \%$ del Fondo Nacional de Cooperación) y administrativas (el expediente de segregación prevé que el hipotético Ayuntamiento de Sant Julià de Cerdanyola no se dotaría de secretario-interventor sino que compartiría el secretario con Guardiola de Berguedà) que resultan del expediente». Recurrido el Decreto 201/1990 ante la Sala de lo Contenciosoadministrativo del Tribunal Superior de Justicia de Cataluña, la Sentencia de su Sección $5 .^{\text {a }}$ de 6 de junio de 1992 declaró la nulidad del mismo y aprobó la segregación municipal de Sant Julià de Cerdanyola. La Generalitat de Cataluña formuló contra esta Sentencia el recurso de casación núm. 583/1992, pero, antes de que se fallase, la Sala competente del Tribunal Superior de Justicia de Cataluña ordenó - por sendos Autos de 6 de octubre y 17 de diciembre de 1992- la ejecución provisional de la Sentencia recurrida. Por este motivo fue dictado el mentado Decreto 172/1993, de 28 de junio, cuyo art. 1 constituyó el nuevo municipio y estableció su denominación y su capitalidad. Por Auto de 7 de julio de 1993, la Sala Tercera del Tribunal Supremo inadmitió el recurso instado por la Generalitat, de modo que el posterior Decreto 65/1994, de 7 de marzo, declaró «definitiva» la segregación de Sant Julià de Cerdanyola, según su artículo único, «desde la fecha de publicación del Decreto 172/1993».

${ }_{8}$ Dejando aparte ciertos ajustes gramaticales, el otro gran cambio que introdujo en el aludido art. 15.1 la Ley 13/1998 fue para concretar el concepto «núcleos de población territorialmente diferenciados» previsto en su apartado a): así, para dar cumplimiento a dicho requisito, pasó a requerirse que hubiera «una zona clasificada como suelo no urbanizable, de una amplitud mínima de 3.000 metros, entre los núcleos más próximos a los municipios resultantes». Ambas exigencias se mantienen hoy, sin variaciones remarcables, en el art. 15.1 del TRLMRLC.

9 Por aquel entonces, sólo estaba tramitándose otro expediente susceptible de verse afectado por los nuevos requisitos: se trataba de la segregación de una parte del término municipal de Alcanar para constituir un nuevo municipio con la denominación de Les Cases de Mar. También sería denegado, en esta ocasión mediante el Decreto 224/2002, de 27 de agosto, tanto por la inexistencia de «núcleos de población territorialmente diferenciados» como por el incumplimiento del mínimo poblacional.

10 Significativamente, en la actualidad, el inciso final del art. 9.4 del Decreto 244/2007 dispone que «las firmas de los vecinos» tendrán que formalizarse «ante el secretario del ayuntamiento o ante notario». 
REALA. Nueva Época - N. ${ }^{\circ}$ 9, Abril 2018 - ISSN: 1989-8975 - DOI: 10.24965/reala.v0i9.10472 - [Págs. 148-164]

La inaudita STC 108/2017, de 21 de septiembre, sobre la Ley del Parlamento de Cataluña 8/2015, de 10 de junio, de creación..

Miquel Pons Portella

precepto que trata de garantizar que la voluntad de los vecinos que suscriben la petición sea cierta, y hasta tal punto es así que algunas pequeñas anomalías que presentaban los documentos a protocolizar [...] dieron lugar a que se redujera el número de firmantes hasta 327. Y éstos claramente expresaban su voluntad de que se iniciara el expediente de segregación de una parte del término municipal de Sant Julià de Ramis, para constituir un nuevo municipio con el nombre de Medinyà. Imponer exigencias que no tienen soporte legal ni reglamentario no es conforme a Derecho y ello determina, como lógica consecuencia, la estimación del presente recurso contencioso-administrativo» (FJ 6. ${ }^{\circ}$ ). En el fallo de esta Sentencia, el Tribunal dispuso, tras anular la resolución, que debía «continuar la tramitación del expediente de segregación».

En aquel momento, empero, ya se hallaba en curso un nuevo expediente para lograr la constitución de Medinyà en municipio independiente, iniciado en este caso por acuerdo del Pleno del Ayuntamiento de Sant Julià de Ramis el día 9 de marzo de 2000. Se recabaron los informes preceptivos del Consejo Comarcal y de la Diputación Provincial, que dictaminaron favorablemente la segregación pretendida, tras lo cual el mismo Pleno municipal aprobó la procedencia de la alteración. El expediente fue remitido al Departamento de Gobernación y Relaciones Institucionales de la Generalitat en fecha 21 de marzo de 2002, pero, al tener que subsanarse varios defectos, la remisión definitiva se demoraría hasta el 11 de julio siguiente. Entonces, el día 6 de noviembre, emitió su informe la Comisión de Delimitación Territorial, que aconsejó la desestimación de la solicitud de Medinyà por carecer de todos los requisitos legales necesarios para constituir un nuevo municipio. En fecha 19 de noviembre, la Generalitat puso en conocimiento de la Administración General del Estado la sustanciación del expediente. Asimismo, el 19 de diciembre, la Comisión Jurídica Asesora -mediante su Dictamen núm. 508/2002- informó desfavorablemente la segregación municipal de Medinyà. Finalmente, para dar cumplimiento a la ya estudiada Sentencia núm. 807/2002, de 30 de octubre, de la Sección 5. a de la Sala de lo Contencioso-administrativo del Tribunal Superior de Justicia de Cataluña, la Dirección General de Administración Local resolvió, en fecha 13 de febrero de 2013, acumular a este expediente -iniciado, recordemos, por el Ayuntamiento de Sant Julià de Ramis- el que habían promovido años antes los propios vecinos de Medinyà.

Así pues, el Decreto 66/2003, de 4 de marzo, resuelve ambos expedientes de segregación. Tras recapitular todos los hechos que quedan relatados, la Generalitat de Cataluña argumenta, por un lado, «que no hay núcleos territorialmente diferenciados, ya que entre los núcleos de población de Sant Julià de Ramis y de Medinyà hay una franja de suelo clasificada como suelo no urbanizable de una anchura de 1.700 metros lineales, no superando la anchura mínima de 3.000 metros exigidos por la Ley 8/1987, de 15 de abril, Municipal y de Régimen Local de Cataluña»; y, por el otro, «que el municipio resultante no tiene población suficiente para asegurar su viabilidad, ya que no contará con una población mínima de 2.000 habitantes, y que no hay una mejora objetiva en la prestación de los servicios» ${ }^{11}$. Por todo ello, con el artículo único del susodicho Decreto 66/2003, «se deniega la segregación de una parte del término municipal de Sant Julià de Ramis para constituir un nuevo municipio con la denominación de Medinyà».

La comisión promotora de la asociación Col·lectiu pro Medinyà Independent interpuso en tiempo y forma recurso contencioso-administrativo ante la Sala competente del Tribunal Superior de Justicia de Cataluña, cuya Sección 5. ${ }^{a}$ lo resolvió mediante la Sentencia núm. 129/2006, de 3 de febrero (recurso contenciosoadministrativo núm. 259/2003). La impugnación se acomete, según leemos en la misma Sentencia, «tanto por razones de forma como de fondo. En cuanto a las primeras, se alega que resulta improcedente la acumulación del expediente incoado por iniciativa de los vecinos al que se inició por parte del Ayuntamiento de Sant Julià de Ramis. Subsidiariamente, considera que la acumulación debió realizarse al expediente más antiguo, esto es, al que se había iniciado a instancia de los vecinos. En último término, se argumenta que el dictamen preceptivo de la Comisión Jurídica Asesora se emitió con anterioridad a la acumulación de ambos expedientes, de modo que aquél no pudo tener en cuenta las alegaciones contenidas en el procedimiento promovido por los vecinos. En cuanto se refiere a las razones de fondo, la actora sostiene que concurren las circunstancias previstas para la segregación de parte del término municipal de Sant Julià de Ramis para constituir el nuevo municipio de Medinyà, a tenor de lo dispuesto en la Ley Municipal y de Régimen Local de Cataluña, en la redacción anterior a la modificación operada por la Ley 13/1998, de 19 de noviembre, que era la vigente en la fecha en que se inició el expediente de segregación promovido por los vecinos» (FJ $\left.1 .^{\circ}\right)$. Ante tales alegatos, la Sala realiza las siguientes consideraciones:

11 Porque, como había recordado la Comisión Jurídica Asesora en el FJ 4. ${ }^{\circ}$ de su aludido Dictamen núm. 508/2002, de 19 de diciembre, «només és procedent la creació d'un municipi si es donen totes les condicions previstes legalment. Només que en falti una, la creació és improcedent». 
- Sobre «la normativa aplicable al caso de autos», empieza el Tribunal Superior de Justicia de Cataluña, «no cabe olvidar que el apartado 2 de la disposición final de la Ley 13/1998, de 19 de noviembre, establece de forma expresa que los requisitos exigidos por dicha Ley para la constitución de nuevos municipios por segregación de otros preexistentes son aplicables a los expedientes que se hallen en tramitación en el momento de la entrada en vigor de la referida Ley. En consecuencia, no cabe duda de que el expediente promovido por la actora debe ser resuelto de acuerdo con las previsiones de la Ley Municipal y de Régimen Local de Cataluña, en la redacción que les dio la citada Ley 13/1998» (FJ 3. $\left.{ }^{\circ}\right)$.

- Por lo que se refiere a «la acumulación del procedimiento promovido por los vecinos y el que se inició por el Ayuntamiento», el Tribunal considera que «resulta plenamente ajustada a Derecho, puesto que ambos versaban sobre el mismo objeto, de modo que resulta plenamente aplicable lo dispuesto en el art. 73 de la Ley del Procedimiento Administrativo Común ${ }^{12}$, que faculta a la Administración para disponer la acumulación de un procedimiento a otro $u$ otros con los que guarde identidad sustancial o íntima conexión» (FJ 4. ${ }^{\circ}$ ).

- A su vez, «tampoco cabe apreciar vicio alguno determinante de la invalidez del Decreto impugnado por el hecho de que el expediente promovido por los vecinos se haya acumulado al que inició el Ayuntamiento, y no a la inversa, pese a haberse incoado aquél con anterioridad». Y ello tanto porque «no resultan de aplicación en este caso las previsiones de la Ley de Enjuiciamiento Civil ${ }^{13}$ », como porque, «desde el momento en que la resolución del procedimiento debe regirse en todo caso por las disposiciones de la Ley 13/1998, [...] es indiferente que la acumulación se haya realizado a uno u otro expediente» (FJ $\left.4 .^{\circ}\right)$.

- En relación con el dictamen preceptivo de la Comisión Jurídica Asesora, «es cierto -admite la Salaque el mismo se emitió con anterioridad a la acumulación del expediente promovido por los vecinos, de modo que aquél no pudo tener en cuenta el contenido de las alegaciones contenidas en éste último. Sin embargo, debe aplicarse en este caso el principio de economía procesal, que impide la retroacción de las actuaciones cuando se considere racionalmente que ello no conducirá a una solución distinta de la que se ha producido. En este caso, la negativa a la constitución del nuevo municipio de Medinyà descansa primordialmente en datos meramente objetivos». Por ello, las conclusiones alcanzadas por la Comisión en su Dictamen núm. 508/2002 «no resultarían alteradas por el contenido de las alegaciones vertidas en el expediente promovido por los vecinos, dado que no han sido puestas en cuestión ni siquiera en el marco de este proceso. En consecuencia, debe considerarse que el Dictamen emitido en su día resulta suficientemente ilustrativo sobre este particular, por lo que ha desestimarse la anulación del Decreto impugnado por este motivo» (FJ $4 .^{\circ}$ ).

- Finalmente, «en cuanto se refiere a la concurrencia de los requisitos exigidos para la constitución de un nuevo municipio por segregación en el art. 15 de la Ley Municipal y de Régimen Local de Cataluña, modificado por la Ley 13/1998», el Tribunal Superior insiste en que «no se dan los previstos en los apartados a) y d) de dicho precepto, puesto que no existe una franja clasificada como suelo no urbanizable, de una anchura igual o superior a los 3.000 metros, entre los núcleos más próximos de los municipios resultantes. Del mismo modo, el nuevo municipio de Medinyà contaría con una población inferior a los 2.000 habitantes, por lo que tampoco se cumple el segundo de los requisitos antes enunciados». Además, «en los dictámenes periciales practicados a instancia de la actora se examina la suficiencia de los recursos económicos con que contaría el nuevo municipio de Medinyà, o sea, el requisito previsto en el art. 15.1 b) [...], pero no se justifica que la segregación haya de comportar una mejora objetiva en la prestación de los servicios en el nuevo municipio, como lo exige además el art. 15.2 de dicha Ley, más allá de una mera referencia genérica a la mayor proximidad del Ayuntamiento que ello comportaría» (FJ $5 .^{\circ}$ ).

Así las cosas, concluye la Sala de lo Contencioso-administrativo del Tribunal Superior de Justicia de Cataluña, «debe desestimarse en su integridad el presente recurso, al resultar ajustado a Derecho el Decreto impugnado».

12 En la actualidad, se trata del art. 57 de la LPAC.

13 Se refiere al art. 84.1 de la LEC, de acuerdo con el cual, «aceptada la acumulación, el tribunal ordenará que los procesos más modernos se unan a los más antiguos, para que continúen sustanciándose en el mismo procedimiento o por los mismos trámites y se decidan en una misma sentencia». 


\subsection{Génesis y contenido de la Ley del Parlamento de Cataluña $8 / 2015$, de 10 de junio}

En un Pleno extraordinario celebrado el 21 de octubre de 2011, todos los grupos municipales del Ayuntamiento de Sant Julià de Ramis acordaron manifestar su «apoyo unánime» a la restitución de la condición de municipio a Medinyà, exhortando además a la Corporación a iniciar gestiones con los partidos del Parlamento de Cataluña con la finalidad de lograr el apoyo necesario para dicha aspiración. A su vez, el 30 de octubre de 2014, el Pleno de la Cámara autonómica aprobó una moción instando al Gobierno a «presentarle el proyecto de ley de creación del municipio de Medinyà, hasta ahora parte del municipio de Sant Julià de Ramis, en El Gironès, en el plazo más breve posible y en paralelo a la tramitación del Proyecto de ley de gobiernos locales de Cataluña». Transcurridos varios meses desde esta iniciativa parlamentaria y dado que -leemos en el preámbulo de la Ley 8/2015- «la legislatura podría acabar antes de lo previsto», "se considera que debe impulsarse la creación del municipio de Medinyà».

En su meritado preámbulo, la Ley 8/2015 -que concibe «la recuperación de la condición de municipio independiente» por parte de Medinyà como un modo de "reparar una decisión antidemocrática, corregir disfuncionalidades y atender a la voluntad de la mayoría de la población»- hace una breve recapitulación de la historia reciente del pueblo, si bien obviando el trascendental dato de que, como hemos visto, en 2003, la propia Generalitat de Cataluña denegó la segregación municipal de este pueblo ${ }^{14}$. Reconoce, es verdad, que «la normativa impide que Medinyà se constituya como municipio independiente» y, por esto, enumera las siguientes circunstancias como justificativas de esta «excepcionalidad de la norma general, que impide la constitución de municipios nuevos cuando no cumplen todos los requisitos legalmente establecidos»:

- «Probablemente como consecuencia de haber sido municipio hasta el año 1972, Medinyà no ha perdido nunca su código postal e, incluso en la señalización de la carretera N-II, de la que se encarga el Ministerio de Fomento, figura el rótulo oficial de "Medinyà"».

- «Con 866 habitantes, Medinyà será el municipio número 123 en número de habitantes de los 222 que conformarán las comarcas de Girona».

- «El estudio económico sobre la viabilidad de los dos núcleos en caso de segregación del pueblo de Medinyà, realizado por la Universidad de Girona, concluye que Medinyà dispone de capacidad para generar recursos suficientes para prestar los servicios necesarios a su población, y, además, dispone ya de todos los servicios básicos obligatorios y de una escuela pública».

- «Medinyà no parte de cero, ya que dispone de todos los servicios necesarios para garantizar el bienestar de los ciudadanos, tanto los servicios de prestación obligatoria por parte del Ayuntamiento, como los servicios voluntarios que son fundamentales para reforzar la vida asociativa y el trabajo comunitario».

La decisión de constituir Medinyà en municipio, «bajo el punto de vista formal», mediante «una ley singular», dado que no es posible -como ya hemos visto- seguir lo dispuesto en el TRLMRLC, se fundamenta tanto en la Constitución de 1978 -se cita, en concreto, su art. 137- como en el capítulo VI del título II del Estatuto de Autonomía de 2006, que está dedicado al «Gobierno Local». El preámbulo de la Ley 8/2015, en su último pasaje, menciona expresamente el art. 83 del Estatuto, que contempla la organización del gobierno local de Cataluña en municipios, veguerías, comarcas y «los demás entes supramunicipales»; y «el principio de diferenciación, como instrumento que configura la potestad legislativa», enunciado en el art. 88 del propio Estatuto: «las leyes que afectan al régimen jurídico, orgánico, funcional, competencial y financiero de los municipios deben tener en cuenta necesariamente las diferentes características demográficas, geográficas, funcionales, organizativas, de dimensión y de capacidad de gestión que tienen» ${ }^{15}$.

14 Al respecto sólo se explica que «en el año 2001 el Informe sobre la organización territorial de Cataluña, encargado por el Gobierno de la Generalidad, integrado por expertos nombrados a propuesta de todos los grupos parlamentarios y presidido por Miquel Roca Junyent, concluyó que debía considerarse el caso de Medinyà dentro el apartado de "Corrección de disfuncionalidades" y proponía el reconocimiento de Medinyà como municipio y recordaba que ya había iniciado un expediente de segregación»

15 Este razonamiento ya fue utilizado en el preámbulo de la Ley 8/2010, la Ley del Parlamento de Cataluña 8/2010, de 22 de abril, de creación del municipio de La Canonja. Se trata de un supuesto muy parecido al que estamos estudiando: un municipio histórico que fue incorporado a la ciudad de Tarragona en 1964, pero mantuvo un «sentimiento de comunidad diferenciada» que le llevó a instar un expediente de segregación que sería denegado en 2009. La diferencia fundamental con Medinyà, como veremos, es que por aquel entonces la normativa del Estado no exigía un mínimum demográfico para la constitución de nuevos municipios, por lo que la Ley $8 / 2010$ ni siquiera sería recurrida ante el Tribunal Constitucional. 
El art. 1 de la Ley 8/2015, que -de acuerdo con su disposición final 2. ${ }^{2}$ - entró en vigor el 16 de junio de 2015, dispone que su objeto «es la creación del municipio de Medinyà por segregación de una parte del término municipal de Sant Julià de Ramis», lo que se acomete mediante cinco artículos, tres disposiciones adicionales, seis disposiciones transitorias y tres disposiciones finales, cuyo contenido es el siguiente:

- Denominación. Según el art. 2.1, «el nombre del nuevo municipio, que adopta la denominación histórica del término y del antiguo municipio, es Medinyà».

- Capitalidad. El propio art. 2.1 establece la capital del nuevo municipio en la localidad Medinyà, dado que -según el art. 3- también forman parte del mismo «los caseríos de Santa Fe de la Serra, Tomet, Lladrers y Vall-llobera».

- Adscripción supramunicipal. De conformidad con el art. 2.2, «el municipio de Medinyà se adscribe a la comarca de El Gironès, a la veguería de Girona y a la provincia de Girona».

- Término municipal. Alcanza 7'66 kilómetros cuadrados y se delimita, en virtud del art. 3, por remisión al «que tenía el antiguo municipio de Medinyà anexionado al municipio vecino de Sant Julià de Ramis el 1972», todo ello de conformidad con el anexo de la Ley 8/2015.

- División y sucesión de bienes, derechos, obligaciones y servicios. En cumplimiento de los apartados 1 y 2 del art. 4 y de la disposición transitoria $3 .^{a}$, Medinyà sucede parcialmente en la titularidad de los bienes, derechos y obligaciones del municipio de Sant Julià de Ramis que le corresponden después de haberse realizado su «división efectiva» por parte de un órgano paritario integrado por el Ayuntamiento de Sant Julià de Ramis y la comisión gestora del nuevo municipio de Medinyà. Dicha división debe asegurar los recursos suficientes para cumplir las competencias municipales y no puede comportar una disminución de la calidad media de los servicios que se prestan. Y, entretanto no se efectúe, los entes locales afectados tienen que garantizar la continuidad de la prestación de todos los servicios y asumir cada uno los compromisos necesarios. Asimismo, la disposición adicional 2. ${ }^{a}$, en su apartado 1, contempla la obligación interadministrativa de «llevar a cabo las actuaciones necesarias para que la titularidad de los bienes, derechos, obligaciones y aprovechamientos que, de acuerdo con la presente ley, deben integrarse en el patrimonio del nuevo municipio sea plena y efectiva».

- Subrogaciones. De acuerdo con el art. 4.3, «el municipio de Medinyà se subroga en los pactos, estipulaciones y convenios suscritos por el Ayuntamiento de Sant Julià de Ramis en todo lo que le afecte».

- Integración del personal. El art. 5 contempla que «una parte del personal funcionario y laboral que presta servicio en el Ayuntamiento de Sant Julià de Ramis», según el pacto alcanzado por el órgano de composición paritaria previsto por la disposición transitoria 3. ${ }^{a}$, se integre «al Ayuntamiento de Medinyà con su condición y situación y con los mismos derechos y deberes que le corresponden de acuerdo con la normativa».

- Participación de la Administración General del Estado. La disposición adicional 1. ${ }^{\text {a }}$ reitera, en su apartado 1, lo previsto por el art. 17.1 e) del TRLMRLC, en el sentido de poner «en conocimiento de la Administración del Estado» la creación del municipio de Medinyà. Sin embargo, el apartado 2 agrega que «la implementación de la presente ley debe ir acompañada, en el plazo de tres meses a contar desde su entrada en vigor, de una valoración y ponderación entre la Administración de la Generalidad y la Administración del Estado que justifique la excepcionalidad respecto a los requisitos para la creación de nuevos municipios establecidos por la legislación básica de régimen local, por tratarse de la restitución de la condición de municipio a un municipio histórico».

- Entrega de expedientes. Por el apartado 2 de la disposición adicional 2. ${ }^{a}$, el Ayuntamiento de Sant Julià de Ramis queda obligado a «entregar al municipio de Medinyà todos los expedientes, tanto concluidos cono en trámite, que afecten al nuevo municipio o se refieran al mismo, así como la documentación necesaria para el funcionamiento normal de la actividad municipal». Este traspaso tiene que realizarse «en el plazo de tres meses a contar desde la entrada en vigor de la presente ley».

- Amojonamiento. De conformidad con la normativa aplicable, según la disposición adicional 3.a , «el departamento competente en materia de administración local y los ayuntamientos de Medinyà y Sant Julià de Ramis deben llevar a cabo el amojonamiento entre los dos municipios en el plazo de un mes a contar desde la creación del municipio de Medinyà».

- Órgano transitorio de gobierno. En virtud de la disposición transitoria $1 .^{a}$, «hasta que no se constituya el consistorio que resulte de las elecciones municipales inmediatamente posteriores a la entrada 
en vigor de la presente ley», que son las que van a celebrarse en mayo de 2019, Medinyà «debe regirse por una comisión gestora de cinco miembros designada por la persona titular del departamento competente en materia de administración local, de acuerdo con los resultados obtenidos en las elecciones municipales anteriores a la entrada en vigor de la ley [las verificadas el 24 de mayo de 2015] en las mesas correspondientes al territorio segregado y atendiendo a criterios de participación equilibrada de mujeres y hombres». Si en la indicada fecha, de acuerdo con la disposición transitoria $6{ }^{a}$, no se hubieren completado «los trámites [...] que implican la participación de la comisión gestora de Medinyà», «sus funciones deben ser ejercidas por el consistorio surgido de dichas elecciones».

- Ordenación urbanística. La disposición transitoria $2{ }^{a}{ }^{a}$ contempla que, «para dotarse de un plan de ordenación urbanística municipal», Medinyà contará con «la asistencia y el apoyo» de «la Administración de la Generalidad y las entidades supramunicipales correspondientes» (apartado 1). Ahora bien, mientras no cuente con una «ordenación urbanística propia» en vigor, "el ámbito territorial de Medinyà queda sujeto a la ordenación y el planeamiento urbanísticos del término municipal de Sant Julià de Ramis (apartado 2). Para el supuesto particular de «las determinaciones de los instrumentos urbanísticos del Ayuntamiento de Sant Julià de Ramis que afectan al término municipal de Medinyà y que se encuentran en tramitación a la entrada en vigor de la presente ley», la disposición transitoria $5 .^{a}$ prevé su adecuación «a la realidad derivada de la creación del municipio de Medinyà».

- Obra pública. Según la disposición transitoria $4 .^{a}$, «las obras públicas promovidas o financiadas por el Ayuntamiento de Sant Julià de Ramis que a la entrada en vigor de la presente ley no han sido recibidas de forma definitiva permanecen bajo titularidad de dicho Ayuntamiento, y pasan, si procede, a titularidad del Ayuntamiento de Medinyà una vez recibidas definitivamente».

\section{EL LITIGIO CONSTITUCIONAL SOBRE LA LEY DE CREACIÓN DEL MUNICIPIO DE MEDINYÀ (STC 108/2017, DE 21 DE SEPTIEMBRE)}

En su reunión del 16 de julio de 2015, la Subcomisión de Seguimiento Normativo, Prevención y Solución de Conflictos de la Comisión Bilateral Generalitat-Estado acordó, de conformidad con el art. 33.2 de la LOTC, «iniciar negociaciones para resolver las discrepancias competenciales suscitadas» entorno a la Ley del Parlamento de Cataluña 8/2015, de 10 de junio. Se creó asimismo, en aquella misma reunión, «un grupo de trabajo para proponer a la Subcomisión la solución que proceda».

Entretanto, por Orden JUS/227/2016, de 16 de febrero, se dispuso la entrada en vigor del Juzgado de Paz de Medinyà, de conformidad con lo previsto por el art. 20.5 de la Ley 38/1988, de 28 de diciembre, de Demarcación y de Planta Judicial ${ }^{16}$. Sin embargo, al poco tiempo de esta decisión, las negociaciones Comisión Bilateral Generalitat-Estado fracasaron definitivamente, por lo que, en fecha 15 de marzo de 2016, el Presidente del Gobierno interpuso el recurso de inconstitucionalidad núm. 1401-2016 contra la referida Ley 8/2015, el cual fue admitido por el Pleno del Tribunal Constitucional mediante Providencia del 12 de abril venidero (antecedentes $1 .^{\circ}$ y $\left.3 .^{\circ}\right)$.

\subsection{Los argumentos del Gobierno}

El Abogado del Estado, actuando en representación -como queda dicho- del Presidente del Gobierno, impugna en exclusiva el art. 1 de la Ley 8/2015. Ello porque «considera que el resto de los artículos y disposiciones de la Ley son instrumentales respecto de éste», de modo que «la inconstitucionalidad del art. 1 [...] debe arrastrar consigo la de todas las demás disposiciones de la Ley impugnada» (antecedente $2{ }^{\circ}$ ).

Así pues, la inconstitucionalidad del art. 1 de la Ley 8/2015 se sustenta por el Gobierno sobre los siguientes dos argumentos:

16 Poco antes había sido aprobada la Orden GRI/357/2015, de 4 de diciembre, por la que se nombra a los vocales gestores que integrarán la comisión gestora municipal que debe constituirse en el municipio de Medinyà. Esta Comisión inició su andadura el 16 de enero de 2016; véase, al respecto, la siguiente noticia: <http://www.govern.cat/pres_gov/AppJava/govern/notespremsa/290195/ consellera-governacio-presideix-constitucio-comissio-gestora-municipal-medinya.html> (consultado el 30 de octubre de 2017). 
REALA. Nueva Época - N. 9 9, Abril 2018 - ISSN: 1989-8975 - DOI: 10.24965/reala.v0i9.10472 - [Págs. 148-164]

La inaudita STC 108/2017, de 21 de septiembre, sobre la Ley del Parlamento de Cataluña 8/2015, de 10 de junio, de creación..

Miquel Pons Portella

\section{La vulneración de la prohibición de regímenes de caso único singulares o particularizados (art. 9 de la LBRL)}

El Abogado del Estado, tras hacer cita expresa de la normativa catalana en materia de régimen local a la que ya nos hemos referido, recuerda «que el propio preámbulo de la Ley impugnada reconoce que "la normativa impide que Medinyà se constituya como municipio independiente" y que ello hace necesario una "ley singular que habilite la excepcionalidad de la norma general que impide la constitución de municipios cuando no se cumplen todos los requisitos legalmente establecidos"». Por ello, y dado además que el "carácter básico» del art. 9 de la LBRL fue reconocido expresamente por la STC 214/1989, de 21 de diciembre, deviene imprescindible «declarar la inconstitucionalidad de la Ley por vulneración del citado art. 9 de la LBRL y, mediatamente, del art. 149.1.18. ${ }^{a}$ de la Constitución».

\section{La vulneración de los requisitos estatales básicos para la creación de nuevos municipios (art. 13.2 de la LBRL)}

El art. 13.2 de la LBRL fue declarado básico por la STC 103/2013, de 25 de abril, lo que ha sido reiterado por la STC 41/2016, de 3 de marzo, en relación con la nueva redacción dada al precepto por la LRSAL, «que -puntualiza el Tribunal- ha añadido significativamente el requisito de que el nuevo término municipal tenga una población mínima de 5.000 habitantes». Por lo tanto, en la medida en que «el propio preámbulo de la Ley catalana reconoce que Medinyà cuenta con 866 habitantes», también es «clara»-según el Abogado del Estado- la infracción del art. 13.2 de la LBRL y, mediatamente, del art. 149.1.18. ${ }^{a}$ de la Constitución.

Por todo ello, insistimos, el Gobierna suplica al Alto Tribunal que se declare inconstitucional y nulo el art. 1 de la Ley 8/2015 y, «por conexión o consecuencia» (art. 39.2 de la LOTC), los demás preceptos -artículos y disposiciones- de la misma Ley.

\subsection{Los argumentos de la comunidad autónoma de Cataluña}

Para defender la constitucionalidad de la Ley 8/2015 formulan alegaciones, en virtud de lo dispuesto por el art. 34.1 de la LOTC, tanto el Letrado del Parlamento de Cataluña (antecedente $6 .^{\circ}$ ) como la Abogada de la Generalitat de Cataluña (antecedente $7 .^{\circ}$ ). Sus razonamientos jurídicos pueden resumirse conjuntamente en los siguientes puntos:

\section{La Ley $8 / 2015$ no crea ex novo el municipio de Medinyà, sino que lo restablece}

Los representantes de la comunidad autónoma de Cataluña realizan largos exordios sobre la historia reciente del pueblo de Medinyà, en los términos que ya quedan explicados, poniendo especial énfasis -en el caso del Letrado del Parlamento- en la «serie de avatares que impidieron que la constitución del municipio de Medinyà se materializara antes de la Ley 13/1998, de 19 de noviembre [...], que estableció diversos criterios restrictivos para la constitución de nuevos municipios inexistentes con anterioridad, [...] y de la LRSAL, que modificó el art. 13 de la LBRL para introducir asimismo el requisito de contar el núcleo de población con un mínimo de 5.000 habitantes».

La Abogada de la Generalitat de Cataluña puntualiza, en este mismo sentido, que «en el denominado "Informe Roca" sobre la revisión del modelo territorial de Cataluña, elaborado por una comisión de expertos en diciembre de 2000 , se proponía igualmente el reconocimiento de ese municipio atendiendo a su realidad local y dilatada trayectoria histórica». Todo ello pondría de manifiesto, en palabras del propio Tribunal, «una fuerte identidad municipal plasmada en sucesivos intentos de segregación» $\left(\mathrm{FJ} 1 .^{\circ}\right)$.

\section{Las reformas introducidas por la LRSAL no pueden tener alcance retroactivo}

El Letrado del Parlamento «sostiene que la Ley recurrida debe beneficiarse de los principios generales aplicables en materia de transitoriedad normativa, que suelen impedir que una ley de reforma despliegue efectos sobre procedimientos iniciados con anterioridad a su entrada en vigor (aunque reconoce que los trámites en sede parlamentaria que condujeron a la aprobación de la Ley 8/2015 son todos ellos posteriores a la entrada en vigor de la LRSAL)». 
REALA. Nueva Época - N. 9 9, Abril 2018 - ISSN: 1989-8975 - DOI: 10.24965/reala.v0i9.10472 - [Págs. 148-164]

La inaudita STC 108/2017, de 21 de septiembre, sobre la Ley del Parlamento de Cataluña 8/2015, de 10 de junio, de creación..

Miquel Pons Portella

En apoyo de su tesis, el mismo Letrado de la Cámara catalana alude a la doctrina mantenida por el Consejo Consultivo de Andalucía durante la tramitación de varios expedientes para la creación de nuevos municipios de menos de 5.000 habitantes «después de la entrada en vigor de la LRSAL, sin que le conste al Letrado del Parlamento que esas segregaciones hayan sido impugnadas ${ }^{17}$. En sus alegaciones, asimismo, la Abogada de la Generalitat de Cataluña insiste, después de recordar que «la LRSAL no contiene disposición transitoria alguna sobre el particular», en que el Estado ha aceptado «que otros procedimientos de alteración del territorio de municipios deben regirse por la legislación vigente en el momento de su iniciación».

\section{La LBRL no resulta aplicable por razones competenciales}

El Letrado del Parlamento de Cataluña rechaza fundamentar esta controversia exclusivamente a partir de la competencia relativa al «régimen local». Y ello porque hay «otro título competencial implicado: el de "organización territorial" resultante de los arts. 148.1.2. ${ }^{\text {a }}$ de la Constitución y 151 del Estatuto de Autonomía de Cataluña. Según estos preceptos corresponde a la comunidad autónoma la competencia "exclusiva" para la "determinación, la creación, la modificación y la supresión de las entidades que configuran la organización territorial de Cataluña" [art. 151, letra a)], entes entre los que se encuentran los municipios según el art. 2.3 del mismo Estatuto de Autonomía, y también para la "creación, la supresión y la alteración de los términos tanto de los municipios como de las entidades locales de ámbito territorial inferior" [art. 151, letra b), primer inciso]». Por ello, el parámetro de contraste de la Ley $8 / 2015$ no puede ser en exclusiva la LBRL, sino que es preciso compatibilizar «esta dualidad de títulos competenciales (régimen local y organización territorial)». El propio Letrado del Parlamento propone llevar a cabo dicha «compatibilización» argumentando «"en el sentido de que las bases del régimen local son operativas cuando se trata de la aplicación de los procedimientos administrativos generales que la legislación local establece para la alteración de términos municipales, pero no en cambio cuando se trata de resolver situaciones especiales y justificadas de naturaleza territorial adoptadas directamente por la ley, supuesto en el cual las bases estatales deben ceder su protagonismo a la competencia de la Generalitat del art. 151 del Estatuto", teniendo en cuenta además que las razones históricas han sido ya consideradas por el Tribunal para justificar regímenes especiales (por ejemplo el de las comarcas de Cataluña, en la STC 214/1989)».

En cambio, la Abogada de la Generalitat de Cataluña «no discute el encuadramiento competencial que lleva a cabo el Estado en su recurso, puesto que indudablemente la creación o restitución de un nuevo municipio se encuadra en la materia de régimen local». Ahora bien, la misma Abogada también «recuerda la doctrina del Tribunal [...] sobre el carácter "bifronte" del régimen local en el ordenamiento constitucional».

\section{El ordenamiento jurídico admite la posibilidad de crear nuevos municipios mediante una ley singular}

La Abogada de la Generalitat de Cataluña explica que «las competencias normativas asumidas en materia de régimen local han sido ejercidas por la Generalitat aprobando su normativa propia de régimen local» ${ }^{18}$, la cual ciertamente contempla - «para la alteración de términos municipales»- «un procedimiento administrativo que culmina con un Decreto del Gobierno de la Generalitat». Pero dicha normativa autonómica, prosigue su argumentación la misma Abogada, «así como el Estatuto de Autonomía de Cataluña (art. 88) e incluso la LBRL (art. 30 [...]), [también] permiten la posibilidad de que la alteración del territorio de un municipio pueda llevarse a efecto por medio de una ley atendiendo a sus características históricas, demográficas, geográficas, funcionales, organizativas y de capacidad de gestión». A su vez, el Letrado del Parlamento de Cataluña afirma, por un lado, que el art. 9 de la LBRL «no trata de prohibir la creación de nuevos municipios, sino de someter a todos ellos al régimen común y ordinario de organización, funcionamiento y actuación que

17 Se trata de Montecorto (Decreto 135/2014, de 30 de septiembre; 667 habitantes), Dehesas Viejas (Decreto 140/2014, de 7 de octubre; 788 habitantes), Serrato (Decreto 167/2014, de 2 de diciembre; 516 habitantes), Játar (Decreto 62/2015, de 3 de febrero; 647 habitantes), Domingo Pérez de Granada (Decreto 105/2015, de 17 de marzo; 921 habitantes) y Balanegra (Decreto 144/2015, de 2 de junio; 2.562 habitantes) (Arroyo Yanes, 2014: 940-943).

18 La Abogada de la Generalitat de Cataluña también menciona, aunque sin profundizar en ello, «que existe una "conexión" entre la competencia sobre las bases del régimen local atribuida al Estado (art. 149.1.18. a de la Constitución) y la garantía institucional de la autonomía local del art. 137 de la Constitución, destacada por la jurisprudencia del Tribunal Constitucional, habiendo mostrado su conformidad con la segregación y constitución de la nueva entidad municipal los dos únicos Ayuntamientos afectados, Sant Julià de Ramis y Medinyà». 
la propia LBRL regula»; y, por el otro, «que la Ley municipal general de Cataluña [...] no puede impedir al mismo legislador catalán aprobar una ley singular para la constitución de un municipio aun sin cumplirse los requisitos establecidos en aquella [...] si considera que hay razones objetivas para ello, como ocurre en este caso atendiendo a las razones históricas expuestas».

Para complementar esta argumentación, ambas representaciones procesales aluden también a «la doctrina del Tribunal sobre el alcance y límites de las leyes singulares, que deben someterse al canon "de la razonabilidad, proporcionalidad y adecuación" [...], y al de la tutela judicial efectiva». Así pues, la Ley 8/2015, teniendo en cuenta su carácter «singular», «no puede tacharse [...] -según el Letrado del Parlamento- de injustificada o arbitraria, ni, en definitiva, de inconstitucional», porque -como concluye la Abogada de la Generalitat- «el Parlamento de Cataluña ha atendido a las circunstancias excepcionales y únicas de Medinyà para restituirle su condición de municipio mediante una ley».

Todos estos motivos, según las representaciones letradas del Parlamento y de la Generalitat de Cataluña, avalan la constitucionalidad de la Ley 8/2015, por lo que solicitan la desestimación del recurso interpuesto por el Presidente del Gobierno.

\subsection{La decisión del Tribunal Constitucional}

El Pleno del Alto Tribunal, tras resumir como de costumbre las tesis de las partes en el FJ $1 .^{\circ}$, hacer pivotar su razonamiento entorno sólo a dos premisas: en primer lugar, soluciona el «punto de partida capital para la resolución de este recurso», que es «el encuadramiento competencial de la decisión controvertida», dado que, si el art. 149.1.18. ${ }^{a}$ de la Constitución tuviese que «quedar desplazado de algún modo» por el art. 151 del Estatuto, «los motivos de inconstitucionalidad esgrimidos en el recurso, que están amparados únicamente en la contravención (mediata) de aquel precepto constitucional ${ }^{19}$, deberían ser directamente rechazados»; y en segundo lugar, atendido «el carácter incontrovertido del incumplimiento por el nuevo municipio del límite mínimo de población establecido en el art. 13.2 de la LBRL», entra a resolver «directamente» el segundo motivo del recurso formulado por el Gobierno.

\section{El «encuadramiento competencial» del litigio (FJ 2. $\left.{ }^{\circ}\right)$}

A la luz de la «doctrina consolidad» del Tribunal Constitucional, «la determinación de los requisitos necesarios para la constitución de un nuevo municipio, que es lo que hace la Ley recurrida, forma parte del contenido de las bases del régimen local que corresponde establecer al Estado conforme al art. 149.1.18. ${ }^{a}$ de la Constitución». Así se declaró por primera vez en la STC 214/1989, de 21 de diciembre, en relación con la «versión originaria» del art. 13 de la LBRL; por segunda vez, en la STC 103/2013, de 25 de abril, en relación con las modificaciones introducidas por la Ley 57/2003, de 16 de diciembre, de medidas para la modernización del Gobierno Local; y, por tercera vez, en la STC 41/2016, de 3 de marzo, en relación con la introducción por la LRSAL de un mínimum de 5.000 habitantes para la constitución de municipios.

En cambio, el art. 151 del Estatuto de Autonomía de Cataluña «tiene un contenido distinto, y se refiere principalmente a la entidad que puede tomar esa decisión [de crear un nuevo municipio]; decisión que no por ello deja de estar sujeta a los requisitos establecidos válidamente en la legislación básica del Estado dictada al amparo del art. 149.1.18. ${ }^{a}$ de la Constitución». El Tribunal Constitucional recuerda, sobre este particular, lo que explicó en el FJ $94 .^{\circ}$ de la STC 31/2010, de 28 de junio, «al enjuiciar la constitucionalidad del citado art. 151 del Estatuto por su supuesto desconocimiento y vulneración del art. 149.1.18. ${ }^{a}$ de la Constitución»: «el art. 151 del Estatuto, bajo la rúbrica "Organización territorial", reconoce a la Generalitat "la competencia exclusiva sobre organización territorial" -comienza la cita textual- [...]. En la letra a) se enuncian unas potestades (determinación, creación, modificación y supresión de las entidades que configuran la organización

19 En la STC 108/2017, el Tribunal no llega a definir la denominada «inconstitucionalidad mediata o indirecta». Sí lo hace, en cambio, en la STC 109/2017, de la misma fecha que la que estamos estudiando: se trata de aquellos supuestos en los que «la posible infracción constitucional [deriva] no de la incompatibilidad directa de las disposiciones impugnadas con la Constitución, sino de su eventual contradicción con preceptos básicos estatales [...]. Según nuestra reiterada doctrina (por todas, STC 82/2017, de 22 de junio, FJ 5), para que dicha infracción constitucional exista será necesaria la concurrencia de dos circunstancias: que la norma estatal infringida por la ley autonómica sea, en el doble sentido material y formal, una norma básica y, por tanto, dictada legítimamente al amparo del correspondiente título competencial que la Constitución haya reservado al Estado; así como, en segundo lugar, que la contradicción entre ambas normas, estatal y autonómica, sea efectiva e insalvable por vía interpretativa» (FJ 2. ${ }^{\circ}$ ). 
territorial de Cataluña) que no conllevan la regulación completa del régimen jurídico regulador de los entes locales que integran la organización territorial de Cataluña, sino que tienen por objeto decisiones concretas a través de las cuales la Generalitat determina, crea, modifica y suprime las entidades locales que han de componer dicha organización territorial, sin que ello impida la plena virtualidad de las bases estatales ex art. 149.1.18. ${ }^{a}$ de la Constitución [...]. A la letra b), que atribuye a la Generalitat diversas potestades sobre los términos de los municipios o entidades de ámbito territorial inferior, así como sobre su denominación, capitalidad, símbolos, topónimos y regímenes especiales, objetan los Diputados recurrentes los mismos vicios de inconstitucionalidad, siendo notorio que las facultades que se reservan a la comunidad autónoma tampoco conllevan la regulación completa de los aspectos indicados. Se trata también aquí de potestades concretas que materializan la configuración de los entes locales de Cataluña de acuerdo con las bases que, en su caso, pueda dictar el Estado».

De este modo «queda claro», concluye el Tribunal Constitucional, «el alcance de las competencias reguladas en ese art. 151 del Estatuto», así como «la plena sujeción de la decisión de crear un nuevo municipio a los requisitos establecidos en la normativa básica válidamente dictada por el Estado al amparo del art. 149.1.18. a de la Constitución».

\section{La vulneración del art. 13.2 de la LBRL (FJ 3.)}

El Tribunal Constitucional recuerda nuevamente, al iniciar la segunda parte de su razonamiento jurídico, que «tanto el preámbulo de la Ley recurrida en los términos antes vistos [...], como los representantes del Gobierno de la Generalitat y del Parlamento de Cataluña en sus escritos de alegaciones [...] reconocen expresamente que Medinyà no cumple con el requisito de población mínima establecido en el art. 13.2 de la LBRL».

Al tratarse de una «norma básica», como queda explicado suficientemente, «de acuerdo con el principio de separación o competencia», el art. 13.2 de la LBRL delimita el ámbito de actuación de la comunidad autónoma y, por tanto, también de su legislador. En consecuencia, siendo este art. 13.2 de la LBRL el precepto estatal de contraste ex art. 149.1.18. ${ }^{a}$ de la Constitución [...], la insalvable contradicción entre ese precepto básico y la decisión tomada por la comunidad autónoma (al amparo del art. 151 del Estatuto, ciertamente, pero sin respetar esa condición o requisito establecido válidamente por el Estado al amparo del citado art. 149.1.18. ${ }^{a}$ de la Constitución) debe conducir directamente a declarar la inconstitucionalidad y nulidad de la Ley del Parlamento de Cataluña 8/2015, de 10 de junio, de creación del municipio de Medinyà».

Al final de la STC 108/2017, el Tribunal Constitucional incluye un breve obiter dictum para desactivar -aunque no resolver- dos de los argumentos sostenidos por el Letrado del Parlamento de Cataluña y por la Abogada de la Generalitat de Cataluña. Sobre las «injusticias» ${ }^{20}$ que se habrían cometido durante «los avatares que impidieron [...] la constitución del municipio de Medinyà», recuerda que «este Tribunal no puede entrar a conocer, ni revisar, procedimientos o resoluciones administrativas o judiciales [...] que denegaron la segregación y constitución de Medinyà como municipio separado de Sant Julià de Ramis [...], pues son decisiones ajenas a su jurisdicción y firmes». Asimismo, en relación con la inaplicación de la LRSAL "por tratarse de una norma posterior a la iniciativa para la segregación y creación del municipio de Medinyà», argumenta el Tribunal que, «aunque asumiera momentáneamente y a efectos meramente dialécticos el alegato de las partes comparecidas, no podría dejar de advertir que la mencionada LRSAL sí estaba en vigor cuando se inició la tramitación parlamentaria de la Ley recurrida [...] e incluso antes, cuando se aprobó la moción 153/X en el Pleno del Parlamento de 30 de octubre de 2014 que según el propio preámbulo de la Ley impugnada (apartado I) está en el origen de su tramitación y aprobación [...]. Por lo tanto, solo por ello perdería ya todo su sustento el alegato sobre la ultraactividad de la redacción anterior de la LBRL por ser la vigente en el momento de iniciarse el "procedimiento" que condujo a la constitución del municipio de Medinyà» ${ }^{21}$ (FJ 3. ${ }^{\circ}$ ).

${ }^{20}$ El Letrado del Parlamento define textualmente la Ley 8/2015 como «una ley de reparación de un acto injusto». Más adelante afirma que la constitución de Medinyà como municipio independiente podría haberse materializado «de no haber mediado esa resolución "injusta" de la Generalitat de Cataluña anulada luego por el Tribunal Superior de Justicia de Cataluña", como hemos visto, en su Sentencia núm. 807/2002, de 30 de octubre [antecedente $6 .^{\circ}$, apartado a)].

${ }^{21}$ Cuando fue éste, precisamente, el fundamento de la doctrina mantenida por el Consejo Consultivo de Andalucía para permitir la segregación de seis nuevos municipios de menos de 5.000 habitantes tras la entrada en vigor de la LRSAL, cuestión a la que -como hemos visto- alude vagamente el Letrado del Parlamento de Cataluña en su escrito de alegaciones. En efecto, al informar el primero de estos expedientes, relativo a la localidad de Montecorto, dicho Consejo -en su Dictamen núm. 609/2014, de 24 de septiembre (FJ 2. ${ }^{\circ}$, apartado 2)- afirmó lo siguiente: «dado que la LRSAL no ha previsto ninguna disposición transitoria respecto de la normativa a aplicar 


\section{CONCLUSIONES}

Los fundamentos y el fallo de la STC 108/2017, de 21 de septiembre ${ }^{22}$, son impecables. No dejan acaso oportunidad para la crítica por cuanto aplican categorías conceptuales bien delimitadas por la jurisprudencia constitucional: las competencias del Estado y de las Comunidades Autónomas en materia de régimen local, la función de las normas básicas y la doctrina de la inconstitucionalidad mediata o indirecta.

Podríamos decir, incluso, que la declaración de nulidad de la Ley del Parlamento de Cataluña 8/2015, de 10 de junio, de creación del municipio de Medinyà era algo previsible, como de otra parte ya pareció presagiar el propio legislador catalán al conceder, mediante el apartado 2 de la disposición adicional $1 .^{a}$ de la Ley anulada, un plazo de tres meses al Estado y a la Generalitat para que efectuasen una «valoración y ponderación» sobre la «excepcionalidad» del caso de Medinyà. Desgraciadamente, dicha negociación -caso de que llegara a producirse- no tuvo ningún éxito, por lo que hoy nos encontramos ante una Ley declarada nula por inconstitucional y, sobre todo, ante un nuevo municipio que dejó de existir el pasado día 31 de enero de 2018.

En atención a la ausencia de una normativa específica para este peculiar supuesto ${ }^{23} \mathrm{y}$ a la inexistencia de precedentes comparables ${ }^{24}$, el procedimiento seguido en fechas muy recientes para dar cumplimiento a la STC $108 / 2017$ presenta un notorio interés ${ }^{25}$, por lo que dejaremos apuntados para acabar sus hitos más remarcables.

En sesión ordinaria celebrada el 29 de noviembre de 2017, la Comisión Gestora Municipal del Ayuntamiento de Medinyà aprobó inicialmente su propia disolución. En el mismo acuerdo también se fijó la fecha a partir de la cual surtiría efectos dicha disolución -31 de enero de $2018^{26}$ - y se nombró una «comisión liquidadora», para «constatar» finalmente la consecuencia primordial de todo ello: la (re)agregación de Medinyà al municipio matriz de Sant Julià de Ramis, aunque sin observar los preceptos del Decreto 244/2007, de 6

a los procedimientos de creación o segregación [...], se considera que, en aras al principio de seguridad jurídica y de irretroactividad normativa, el criterio interpretativo debe ser el de que los procedimientos administrativos iniciados con anterioridad a la entrada en vigor de la LRSAL se resolverán de acuerdo con la normativa vigente en el momento de su iniciación», la cual -dicho sea de paso- sí permitía tales segregaciones. Esta posición, enormemente cautelosa y que fue contestada en el propio seno del Consejo Consultivo mediante la emisión de varios votos particulares, sería mantenida en lo sucesivo tanto para avalar otras segregaciones, a las que ya nos hemos referido, como para rechazarlas; este ha sido el caso, en efecto, de Fuente Carreteros (Dictamen núm. 299/2015, de 29 de abril), La Guijarrosa (Dictamen núm. 426/2015, de 17 de junio) y San Martín de Tesorillo (Dictamen núm. 754/2015, de 18 de noviembre) (PonsPortella, 2016: epígrafe 3.2).

22 Publicada en el BOE núm. 247, 13 de octubre de 2017, Suplemento del Tribunal Constitucional, págs. 99.726-99.734. Un extracto con su fallo aparecería en el DOGC núm. 7494, 14 de noviembre de 2017.

23 El art. 3.1 del Decreto 244/2007, de 6 de noviembre, contempla sólo cuatro supuestos de alteración de términos municipales: agregación total, fusión, segregación parcial para constituir un municipio independiente y segregación parcial para agregarse a otro municipio. También se prevé, en el art. 3.2, la alteración para corregir «disfunciones territoriales» de art. 12.3 del TRLMRLC.

24 El municipio murciano de Los Alcázares fue creado por Decreto 77/1983, de 13 de octubre, el cual sería declarado nulo por la Sala Tercera del Tribunal Supremo en su Sentencia de 30 de mayo de 1989. La Asamblea Regional de Murcia reaccionó inmediatamente aprobando la Ley 4/1989, de 28 de julio, que volvió a crear el sobredicho municipio con efecto retroactivo -según su art. 4- «al día 17 de octubre de 1983» (Gutiérrez Llamas, 1990: passim). En fechas más recientes, la Sección 1. a de la Sala de lo Contenciosoadministrativo del Tribunal Superior de Justicia del País Vasco, con su Sentencia núm. 11/2016, de 25 de enero (recurso contenciosoadministrativo núm. 8/2014), ha anulado el Decreto Foral 46/2013, de 17 de diciembre, por el que se aprueba la segregación del núcleo de población de Igeldo perteneciente al municipio de San Sebastián y su constitución en un nuevo municipio independiente. Este Decreto, sin embargo, se hallaba suspendido desde el Auto de 12 de febrero de 2014, con el que la misma Sala tomó dicha medida cautelar precisamente para evitar que el municipio de San Sebastián tuviese, llegado el caso, que «reabsorber el núcleo de Igeldo ya para entonces creado en la práctica» (FJ 4. ${ }^{\circ}$ ) (Pons-Portella, 2016: epígrafe 3.1).

25 Acrecido si cabe por la situación jurídico-política resultante del Acuerdo del Pleno del Senado de 27 de octubre de 2017 , por el que se aprueban las medidas requeridas por el Gobierno, al amparo del artículo 155 de la Constitución, para que la Generalitat de Cataluña proceda al cumplimiento de sus obligaciones constitucionales y a la cesación de sus actuaciones gravemente contrarias al interés general. Ciertamente, el art. 151 del Estatuto de Autonomía de Cataluña, en su apartado b), le atribuye a la Generalitat la «competencia exclusiva» para «la creación, la supresión y la alteración de los términos tanto de los municipios como de las entidades locales de ámbito territorial inferior», pero tras el Real Decreto 944/2017, de 27 de octubre, dichas funciones han sido ejercidas por el Ministerio de la Presidencia y para las Administraciones Territoriales. Buena muestra de ello son el Real Decreto 1066/2017, de 22 de diciembre, por el que se aprueba la alteración de los términos municipales de Sant Just Desvern y de Esplugues de Llobregat; el Real Decreto 1067/2017, de 22 de diciembre, por el que se aprueba la alteración de los términos municipales de Sant Quintí de Mediona y de Mediona; el Real Decreto 1068/2017, de 22 de diciembre, por el que se aprueba la alteración de los términos municipales de Granera y de Gallifa; y el Real Decreto 1069/2017, de 22 de diciembre, por el que se deniega la alteración de los términos municipales de Lluçà y de Prats de Lluçanès.

${ }_{26}$ El mismo día también fue elegido para que se produjese «la efectividad del cese de actividad del juzgado de paz de Medinyà», de conformidad con el art. 2 de la Orden JUS/72/2018, de 29 de enero, por la que se dispone el traslado del Registro Civil y de todos los medios materiales del extinto Juzgado de Paz de Medinyà (Girona). Según su art. 1, dicho traslado es al Juzgado de Paz de Sant Julià de Ramis. 
REALA. Nueva Época - N. 9 9, Abril 2018 - ISSN: 1989-8975 - DOI: 10.24965/reala.v0i9.10472 - [Págs. 148-164]

La inaudita STC 108/2017, de 21 de septiembre, sobre la Ley del Parlamento de Cataluña 8/2015, de 10 de junio, de creación..

Miquel Pons Portella

de noviembre. Así, la Comisión Gestora se limitó a conceder un plazo de 30 días -a contar desde la publicación del acuerdo ${ }^{27}$ - para audiencia de «organismos y proveedores» y como trámite de información pública para los demás interesados. La disolución de la Comisión Gestora Municipal del Ayuntamiento de Medinyà sería aprobada definitivamente en una nueva sesión ordinaria verificada el 31 de enero de 2018, durante la cual también se adoptaron otros acuerdos complementarios: la liquidación patrimonial, la destinación del personal municipal y, entre algunos más, la sucesión universal del Ayuntamiento de Sant Julià de Ramis en todos los bienes, derechos y obligaciones de Medinyà. Dicho acuerdo ${ }^{28}$ contiene un pie de recurso, tanto para la vía administrativa -mediante una reposición (potestativa) que debería interponerse ante el Pleno del Ayuntamiento de Sant Julià de Ramis- como para la vía contencioso-administrativa. Sin embargo, no hay constancia, por el momento, de que el procedimiento seguido para la supresión del municipio de Medinyà, en cumplimiento a la STC 108/2017, haya sido impugnado.

\section{REFERENCIAS BIBLIOGRÁFICAS}

AMENÓS ÁLAMO, J. (2014): "El elemento territorial del municipio en la Ley 27/2013, de Racionalización y Sostenibilidad de la Administración Local", Anuario del Gobierno Local 2013, Barcelona: Fundación Democracia y Gobierno Local. Instituto de Derecho Público.

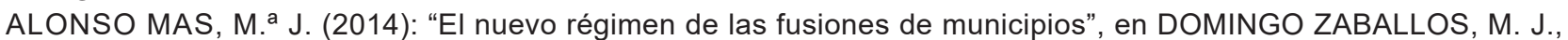
Reforma del régimen local. La Ley de racionalización y sostenibilidad de la administración local: veintitrés estudios, 297-328, Navarra, Cizur Menor: Aranzadi Thomson Reuters.

ARROYO YANES, L. M. (2014): "Incidencia general de la LRSAL sobre el régimen local de Andalucía", en QUINTANA LÓPEZ, T., La reforma del régimen local. Comentario a la Ley 27/2013, de 27 de diciembre, de racionalización y sostenibilidad de la Administración Local, 922-963, Valencia: Tirant lo Blanch.

BOIX PALOP, A. (2014): "Sentido y orientación de la Ley 27/2013 de racionalización y sostenibilidad de la Administración local: autonomía local, recentralización y provisión de servicios públicos locales", Revista de Estudios de la Administración Local y Autonómica. Nueva época (2). http://dx.doi.org/10.24965/reala.v0i2.10199.

COSCULLUELA MONTANER, L. (2013): "Reforma de la Administración Local. Una oportunidad de modificar la planta municipal que no puede perderse", Revista Española de Derecho Administrativo (157): 11-19.

Esculín Palop, C. (2011): "La alteración de los términos municipales", en MUÑOZ MACHADO, S., Tratado de derecho municipal, II, 1.849-1.942, Madrid: lustel.

GALÁN GALÁN, A. (2015): "La aplicación autonómica de la Ley de Racionalización y Sostenibilidad de la Administración Local", Revista de Estudios de la Administración Local y Autonómica: Nueva Época (número extraordinario). DOI: http://dx.doi.org/10.24965/reala.v0iExtra.10225.

GUTIÉRREZ LLAMAS, A. (1990): "Competencia para la creación, modificación y alteración de términos municipales: el caso de Los Alcázares. (Comentario a la sentencia del Tribunal Supremo, Sala Tercera, de 30 de mayo de 1989 y la intervención posterior del legislador)", Revista de Estudios de la Administración Local y Autonómica (245): 147-168. DOI: $h$ ttp://dx.doi.org/10.24965/reala.vi245.8632.

MARTÍNEZ GUTIÉRREZ, R. (2014): "El impacto de la reforma de la LRBRL en la Comunidad Valenciana", en QUINTANA LÓPEZ, T., La reforma del régimen local. Comentario a la Ley 27/2013, de 27 de diciembre, de racionalización y sostenibilidad de la Administración Local, 855-921, Valencia: Tirant lo Blanch.

MEDINA ALCOZ, L. (2017): "La distribución de competencias entre el Estado y las comunidades autónomas a la luz de las sentencias constitucionales sobre la reforma local de 2013", Anuario del Gobierno Local 2015/2016, Barcelona: Fundación Democracia y Gobierno Local. Instituto de Derecho Público.

MELLADO RUIZ, L. (2014): Génesis y realidad de la Ley 27/2013, de 27 de diciembre, de Racionalización y Sostenibilidad de la Administración Local: ¿una nueva reforma económica local? Granada: CEMCI.

ORDUÑA REBOLLO, E. (2005): Historia del municipalismo español, Madrid: lustel.

PONS-PORTELLA, M. (2016): "La población mínima de los nuevos municipios: estado de la cuestión tras la Ley de Racionalización y Sostenibilidad de la Administración Local", Revista de Estudios de la Administración Local y Autonómica. Nueva Época (5). DOI: http://dx.doi.org/10.24965/reala.v0i5.10353.

QUINTANA LÓPEZ, T. (2014): "Debate previo a la reforma de la legislación del Estado de Régimen Local”, en QUINTANA LÓPEZ, T., La reforma del régimen local. Comentario a la Ley 27/2013, de 27 de diciembre, de racionalización y sostenibilidad de la Administración Local, 23-71, Valencia: Tirant lo Blanch.

RAZQUÍN LIZARRAGA, M. M. ${ }^{a}$ (2014): "Reforma local y derechos históricos: Navarra y País Vasco", en DOMINGO ZABALLOS, M. J., Reforma del régimen local. La Ley de racionalización y sostenibilidad de la administración local: veintitrés estudios, 117-152, Navarra, Cizur Menor: Aranzadi Thomson Reuters.

27 DOGC núm. 7.516, 14 de diciembre de 2017.

28 DOGC núm. 7.560, 16 de febrero de 2018. 
REALA. Nueva Época - N. 9, Abril 2018 - ISSN: 1989-8975 - DOI: 10.24965/reala.v0i9.10472 - [Págs. 148-164]

La inaudita STC 108/2017, de 21 de septiembre, sobre la Ley del Parlamento de Cataluña 8/2015, de 10 de junio, de creación..

Miquel Pons Portella

SAN MARTÍN SEGURA, D. (2010): "La alteración de los términos municipales en La Rioja y la defensa de la autonomía local. Consideraciones a partir de la segregación del exclave de Somalo", Anuario Jurídico de La Rioja (15): 219-299. Disponible en web: https://publicaciones.unirioja.es/ojs/index.php/ajr/article/view/873/765 (consultado el 5 de noviembre de 2017).

SANTAMARÍA PASTOR, J. A. (coord., 2014): La reforma de 2013 del régimen local español. Barcelona: Fundación Democracia y Gobierno Local.

VELASCO CABALLERO, F. (2014): "El nuevo régimen local general y su aplicación diferenciada en las distintas comunidades autónomas", Revista catalana de dret públic (48): 1-23.

VELASCO CABALLERO, F. (2014): "La ley de racionalización y sostenibilidad de la Administración local en el sistema de derecho local”, en DOMINGO ZABALLOS, M. J., Reforma del régimen local. La Ley de racionalización y sostenibilidad de la administración local: veintitrés estudios, 43-81, Navarra, Cizur Menor: Aranzadi Thomson Reuters. 